\title{
Contractual Agreement
}

National Cancer Institute

\section{Source}

National Cancer Institute. Contractual Agreement. NCI Thesaurus. Code C115464.

A leg ally binding accord between two or more people that details any and all arrangements regarding a specific situation(s). 